\title{
End-chain and Mid-chain Functional Macrophotoinitiators of Poly ( $\varepsilon$-caprolactone) and Their Molar Mass Effects on Strong Electrorheological Response
}

\author{
Hasim YILmaz, ${ }^{1, \dagger}$ Mustafa DeĞirmenci, ${ }^{1}$ Ümmihan YILMAZ, ${ }^{2}$ and Halil Ibrahim UNAL ${ }^{2}$ \\ ${ }^{1}$ Harran University, Science Faculty, Chemistry Department, Osmanbey, 63190 Sanliurfa/TURKEY \\ ${ }^{2}$ Gazi University, Science Faculty, Chemistry Department, Teknikokullar, 06500 Ankara/TURKEY
}

(Received June 1, 2006; Accepted October 11, 2006; Published November 24, 2006)

\begin{abstract}
Electrorheological (ER) fluids are suspensions composed of ionomer solid particles dispersed in insulating liquids, which show abrupt changes of rheological properties under the stimulation of an external electric field. In this study, electrical and ER properties of end-chain and mid-chain functional macrophotoinitiators of poly( $\varepsilon$-caprolactone) were investigated. For this purpose 4 different samples of poly( $\varepsilon$-caprolactone) were synthesized with different molar masses. They were then ground milled for a few hours to obtain micron size. The particle sizes of the poly $(\varepsilon$-caprolactone)s were determined by dynamic light scattering. Suspensions of poly( $\varepsilon$-caprolactone $)$ s were prepared in silicone oil (SO), at a series of concentrations $(c=5-20 \%, \mathrm{~m} / \mathrm{m})$. The gravitational stability of suspensions against sedimentation was determined at constant temperature $\left(T=25^{\circ} \mathrm{C}\right)$. Flow times of the suspensions were measured under no electric field $(E=0 \mathrm{kV} / \mathrm{mm})$, and under an external applied electric field $(E \neq 0 \mathrm{kV} / \mathrm{mm})$ strengths and a strong ER activities were observed for all the poly( $\varepsilon$-caprolactone)s/SO suspensions. Further, the effects of suspension concentration, molar mass of the poly( $\varepsilon$-caprolactone)s, shear rate, electric field strength, frequency, promoter and temperature onto ER activities of suspensions were investigated. [doi:10.1295/polymj.PJ2006048]

KEY WORDS Electrorheological Fluids / Ring-Opening Polymerization (ROP) / Poly( $\varepsilon$-caprolactone) / Molar Mass / Shear Stress /
\end{abstract}

Electrorheological (ER) fluids display remarkable rheological behavior, being able to convert rapidly and repeatedly from a fluid to a solid-like when an external electric field $(E)$ is applied or removed. The wide potential of ER fluids in industrial applications have been attracted much attention, and a great deal of research activities has been carried out in this area. ${ }^{1,2}$ However, as have been usually recognized, the luck of ER fluids with strong ER effect has become the bottleneck of the development of ER technology, which includes materials design, preparation, and characterization, application establishment and controlling. ${ }^{3}$ Electrorheological fluids have attracted much industrial attention because of their possible use in devices such as valves, dampers, clutches, brakes and robotic actuators. ${ }^{4,5}$ Industrially desired shear stress of ER fluids is usually reported to be not less than $5 \mathrm{kPa}$ under low shear rates. ${ }^{6}$

We have recently reported the preparation of ER active suspensions composed of poly(Li-2-hydroxyethyl methacrylate)/SO system, which shown a good ER response with a $\tau=13.75 \mathrm{kPa}$ shear stress. ${ }^{7}$ To further enhance the ER properties of ER system we prepared a new series of poly( $\varepsilon$-caprolactone), and reported the synthesis, characterization and ionomer preparation in an our earlier article. ${ }^{8}$ For this ER active ionomer suspensions, the high dielectric constant
(933) and conductivity ratios $\left(3.88 \times 10^{-8} \mathrm{Sm}^{-1}\right)$ between particles and SO have been considered to be responsible for the strong ER effect ( $\tau=7.4 \mathrm{kPa}$ ).

However, to prepare ER fluids with predictable ER strength, factors affecting the ER response should be properly interpreted. As well known, ER effect is influenced by many factors: such as dielectric properties of particles and insulating oils, external electric field strengths, particle concentration, particle size, environmental temperature, promoter and frequency. ${ }^{9,10}$ Different models have been developed to describe the concentration effect. ${ }^{11,12}$ The polarization model describes that shear stress of ER fluids is proportional to the concentration of the particles. However, among these factors, molar mass of the dispersed polymeric particles is one of the most important factors that greatly affect the shear stress and sedimentation stability of ER suspensions. Although there are several reports of ER fluids with high shear stresses, ${ }^{13,14}$ the molar mass effect on ER phenomenon has not been quantitatively discussed yet.

In this paper, the overall molar mass of the polymeric and particle concentration effects on ER fluids with strong ER response has been studied. The photofunctional $\operatorname{poly}(\varepsilon$-caprolactone) polymers have been coded with letters A, B, C, and D according to their synthesis order. ${ }^{8}$ 
Molar Mass Effects on Electrorheological Response of PCL

Table I. Synthesis of photoactive poly $(\varepsilon \text {-caprolactone })^{\mathrm{a}}$

\begin{tabular}{cccccccc}
\hline run & initiator & $\begin{array}{c}{[\mathrm{I}] \times 10^{2}} \\
\left(\mathrm{~mol} \mathrm{~L} \mathrm{~L}^{-1}\right)\end{array}$ & $\begin{array}{c}\text { Time } \\
(\mathrm{h})\end{array}$ & polymer & $\begin{array}{c}\text { Conversion } \\
(\%)\end{array}$ & $M_{\mathrm{n} \text { GPC }}$ & $M_{\mathrm{w}} / M_{\mathrm{n}}$ \\
\hline A & HMPP & 41 & 48 & HMPP-PCL & 90 & 2600 & 1.08 \\
B & B & 45 & 72 & B-PCL & 84 & 2500 & 1.13 \\
C & B & 45 & 96 & B-PCL & 100 & 3300 & 1.57 \\
D & HE-HMPP & 22 & 90 & HE-HMPP-PCL & 100 & 4400 & 1.56 \\
\hline
\end{tabular}

${ }^{\mathrm{a}}$ Temperature $=110{ }^{\circ} \mathrm{C},[\varepsilon-\mathrm{CL}]_{\mathrm{o}}$ ) $9.02 \mathrm{~mol} \mathrm{~L}^{-1}$ (in bulk), $[\mathrm{I}] /[\varepsilon-\mathrm{CL}]$ ) $1 / 20$ and $\left[\mathrm{Sn}(\mathrm{Oct})_{2}\right] /[\mathrm{I}]$ ) $1 / 400$ for the initiators HMPP and B, and $[\mathrm{I}] /[\varepsilon-\mathrm{CL}]) 1 / 40$ and $\left.\left[\mathrm{Sn}(\mathrm{Oct})_{2}\right] /[\mathrm{I}]\right) 1 / 200$ for the initiator HE-HMPP.

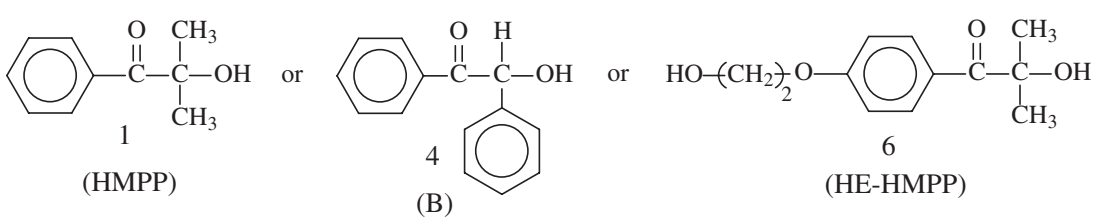

(B)

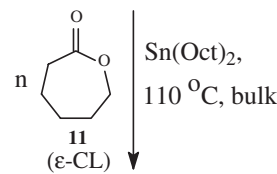

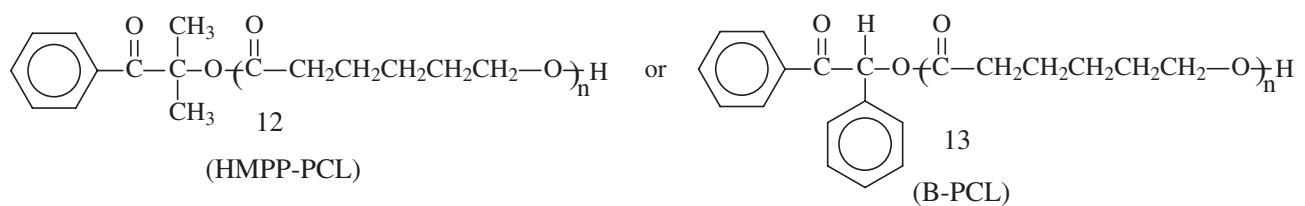
or

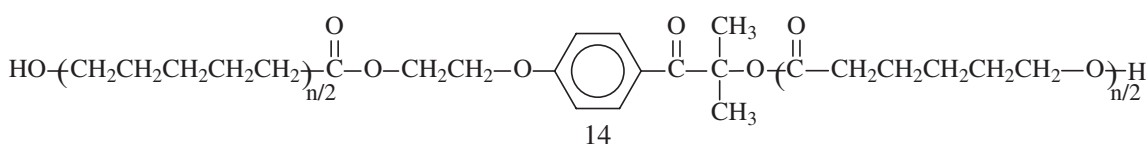

(HE-HMPP-PCL)

Scheme 1. Preparation of macrophotoinitiators of poly( $\varepsilon$-caprolactone) by living ring-opening polymerization (ROP) method.

\section{EXPERIMENTAL}

\section{Materials}

The silicone oil, SO, was used after drying at $130{ }^{\circ} \mathrm{C}$ for $24 \mathrm{~h}$ in a vacuum oven, to remove any moisture present. All the chemicals were Aldrich (Aldrich Chemicals, Steinheim, Germany) products, with analytical grade.

\section{Preparation of End-chain and Mid-chain Functional Macrophotoinitiators of Poly( $\varepsilon$-caprolactone)}

Certain amounts of monomer ( $\varepsilon$-caprolactone, $\varepsilon$-CL), stannous-2-ethylhexanoate $\left(\mathrm{Sn}(\mathrm{Oct})_{2}\right)$ and photoinitiators namely 2-hydroxy-2-methyl-1-phenyl propan-1-one, HMPP, benzoin, B, and 2-hydroxy-1[4-(2-hydroxyethoxy)phenyl]-2-methyl propan-1-one, HE-HMPP, were added under nitrogen into previously flamed and nitrogen-purged Schlenk tubes equipped with a magnetic stirrer. The polymerization conditions are given in Table I. The $\varepsilon$-CL polymerizations were carried out in bulk at $110^{\circ} \mathrm{C}$. After given time the mixtures were diluted with $\mathrm{CH}_{2} \mathrm{Cl}_{2}$ and poured into 10-fold excess of cold methanol. The polymers were collected after filtration and drying at room temperature in a vacuum for $3 \mathrm{~d}$.

In Scheme 1 and Table I synthesis of end-chain and mid-chain functional macrophotoinitiators of $\operatorname{poly}(\varepsilon-$ caprolactone) by living ring-opening polymerization (ROP) method and the characteristic of the investigated polymers are given. The detailed polymerization conditions and characterization processes were given in previous article. ${ }^{8}$

\section{Particle Size Measurements}

The average diameters of particles of A, B, C, and D polymer were determined by Fraunhofer scattering using a Malvern Mastersizer E, version 1.2b particle size analyzer. The samples were dispersed in distilled water and stirred at a constant temperature of $25^{\circ} \mathrm{C}$. The data collected were evaluated according to Fraunhofer diffraction theory by the Malvern software computer. ${ }^{15}$ From these measurements $\mathrm{d}_{50}=8.0-25$ $\mu \mathrm{m}$ average particle sizes were determined for the 


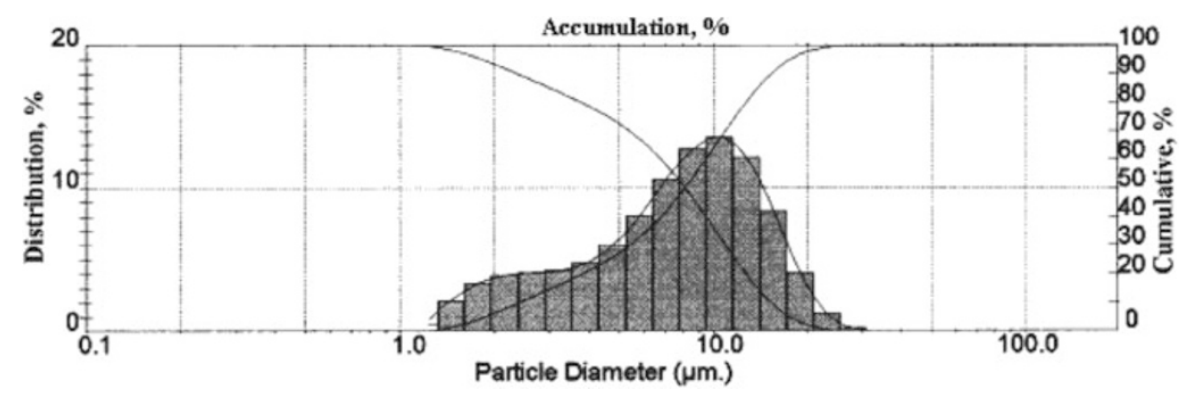

Figure 1. The particle size distribution histogram for D/SO.

ionomers. In this article just $\mathrm{d}_{50}=5.0 \mu \mathrm{m}$ average particle sized ionomers were studied. The particle size distribution histogram just for $\mathrm{D}$ polymer is given in Figure 1.

\section{Preparation of Suspensions}

The base fluid was silicone oil (SO) provided with a specific gravity of $0.97 \mathrm{~g} / \mathrm{cm}^{3}$, a dielectric constant of 2.61 and a viscosity of $150 \mathrm{mPas}$ at $25^{\circ} \mathrm{C}$. Prior to mixing with $\mathrm{SO}$, all the ionomer particles were dried at $150^{\circ} \mathrm{C}$ for $24 \mathrm{~h}$ and $\mathrm{SO}$ at $130^{\circ} \mathrm{C}$ for overnight to remove any moisture present in a vacuum oven $(\mathrm{P}=$ $15 \mathrm{mmHg}$ ). Ionomer/SO suspensions were then prepared at a series of concentrations $(c=5-20 \%, \mathrm{~m} / \mathrm{m})$.

\section{Determination of Colloidal Stability}

The gravitational stability of suspensions $(c=$ $5-20 \%, \mathrm{~m} / \mathrm{m}$ ) against sedimentation was determined at constant temperature $\left(25^{\circ} \mathrm{C}\right)$. Glass tubes containing each concentration of the suspensions were immersed into a constant temperature water bath and formation of first precipitates at the bottom of the tubes was taken to be the indication colloidal instability.

\section{Electrorheometry}

Rheological experiments were carried out on the suspensions, for the experimental determination of flow behavior and visco-elastic material properties, which influence processing technology and polymers stability and consistency. Flow rate measurements of ionomers/SO system were carried out between two parallel plate brass electrodes. The gap between the electrodes was $0.5 \mathrm{~cm}$, the width of the electrodes was $1.0 \mathrm{~cm}$ and the height of suspension on the electrodes was $5.0 \mathrm{~cm}$. During the measurements these electrodes were connected to a high voltage dc electric source $(0-12.5 \mathrm{kV}$ with $0.5 \mathrm{kV}$ increments, Fug Electronic HCL-14, Germany) and a digital voltmeter.

At the beginning of the experiment, the electrodes were dipped into a vessel containing the ER suspension and after a few seconds the vessel was removed and the flow time for complete drainage measured using a digital stop-watch $(E=0.0 \mathrm{kV} / \mathrm{mm})$. At the sec- ond stage, the electrodes were again dipped into the same vessel containing the ER fluid and subjected to an external high voltage $(E \neq 0.0 \mathrm{kV} / \mathrm{mm})$. After several seconds the vessel was removed and the flow time for complete drainage of the liquid between the electrodes measured under the applied electric field. This procedure was repeated for each ER ionomer suspension sample under various external electric field strengths $(E=0.5-2.0 \mathrm{kV} / \mathrm{mm}$ with $0.5 \mathrm{kV} / \mathrm{mm}$ increments). The flow rate measurements were undertaken at ambient temperature.

Electrorheological properties of the ionomer suspensions were tested by Thermo-Haake RS600 rheostress electro-rheometer in controlled stress (CS) mode at a shear rate range of $0.001-1500 \mathrm{~s}^{-1}$, using $35 \mathrm{~mm}$ plate to plate geometry electrodes with a $1.0 \mathrm{~mm}$ gap. All the experiments were carried out at various temperatures $\left(T=25-125^{\circ} \mathrm{C}\right)$. The voltage used in these experiments was supplied by an external dc electric field generator $(0-12.5 \mathrm{kV}$, with $0.5 \mathrm{kV}$ increments), which enabled resistivitiy to be created during the measurements.

\section{RESULTS AND DISCUSSIONS}

\section{Colloidal Stability of Suspensions}

When the density of particles is not as same as that of medium, the particles with micron order size will settle down according to the Stoke's law. ${ }^{16}$ In order to solve the traditional problem of particle sedimentation, several researchers have developed different solutions. ${ }^{17}$ Density mismatch between dispersed and continuous phase plays an important role in sedimentation stability of an ER fluid. Before ER measurements to be carried out, colloidal stabilities of all the ionomers studied in this work were determined in $\mathrm{SO}$ at $25^{\circ} \mathrm{C}$, and results obtained are tabulated in Table II. The sedimentation ratios of ionomer/SO systems are also given in Figure 2 for $c=20 \%$ suspension concentrations.

As seen from the table, colloidal stabilities of suspensions were increased with decreasing particle concentration. Maximum colloidal stability was found to 
Table II. Colloidal stability of ionomers in SO $\left(T=25^{\circ} \mathrm{C}\right)$

\begin{tabular}{ccccc}
\hline \multicolumn{5}{c}{ Concentration $(\mathrm{m} / \mathrm{m})$} \\
\hline Ionomers & $5 \%$ & $10 \%$ & $15 \%$ & $20 \%$ \\
A & $17 \mathrm{~d}$ & $15 \mathrm{~d}$ & $14 \mathrm{~d}$ & $11 \mathrm{~d}$ \\
$\mathrm{~B}$ & $15 \mathrm{~d}$ & $12 \mathrm{~d}$ & $11 \mathrm{~d}$ & $11 \mathrm{~d}$ \\
$\mathrm{C}$ & $20 \mathrm{~d}$ & $18 \mathrm{~d}$ & $15 \mathrm{~d}$ & $11 \mathrm{~d}$ \\
$\mathrm{D}$ & $21 \mathrm{~d}$ & $19 \mathrm{~d}$ & $16 \mathrm{~d}$ & $12 \mathrm{~d}$ \\
\hline
\end{tabular}

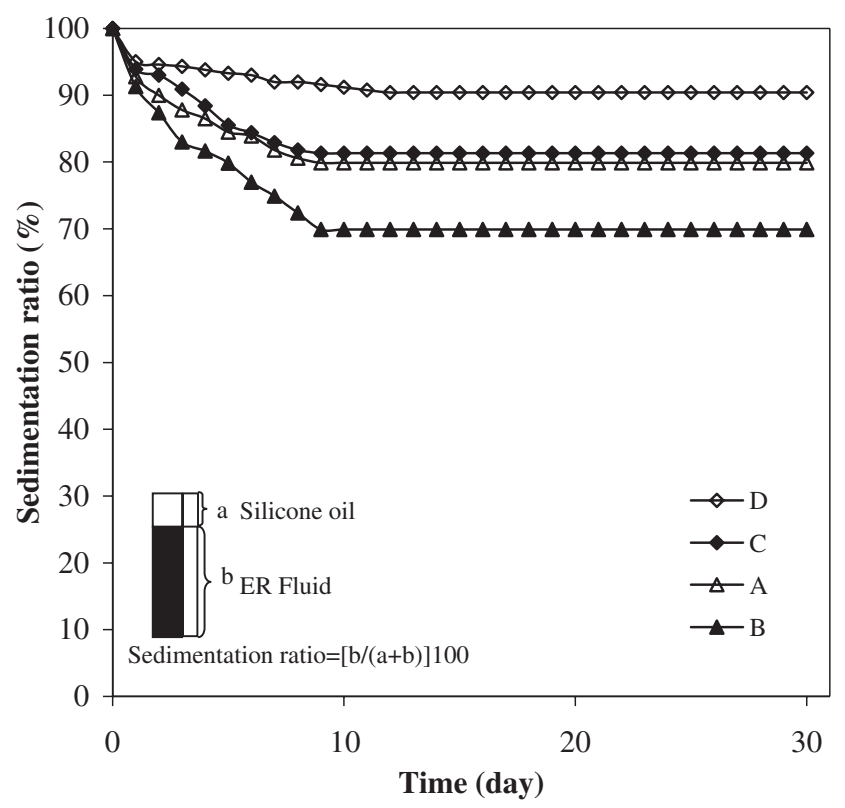

Figure 2. Sedimentation ratios of ionomers, $(c=20 \%, \mathrm{~m} / \mathrm{m}$, $\left.T=25^{\circ} \mathrm{C}\right)$.

be $21 \mathrm{~d}$ for $\mathrm{D} / \mathrm{SO}$ suspension at $c=5 \%$ concentration. It was observed from Table II and Figure 2 that, as the molar mass of poly( $\varepsilon$-caprolactone) increases, colloidal stabilities and sedimentation ratios of the ionomers also increase. This may be attributed to the formation of micellar aggregates in SO and also an interaction between ionic part of the ionomer particles and SO (Figure 3). This $21 \mathrm{~d}$ sedimentation stability was low when compared to the sedimentation stability of poly(Li-2-hydroxyethyl methacrylate)/SO system, which shown a maximum of $60 \mathrm{~d}$ gravitational stability. ${ }^{7}$ These expected results are in accordance with the earlier studies reported in the literature. ${ }^{18,19}$

\section{Electrorheology}

Results Obtained from Parallel Plate Electrodes

Flow times of ionomers suspensions, prepared in $\mathrm{SO}$ at the concentration range of $c=5-20(\%, \mathrm{~m} / \mathrm{m})$, measured between the parallel plate brass electrodes at zero applied field $(E=0 \mathrm{kV} / \mathrm{mm})$ and under various applied electric field strengths $(E=0-1.8 \mathrm{kV} /$ $\mathrm{mm}$ ) are shown in Figure 4.

As seen from the figure, first gradual increase in

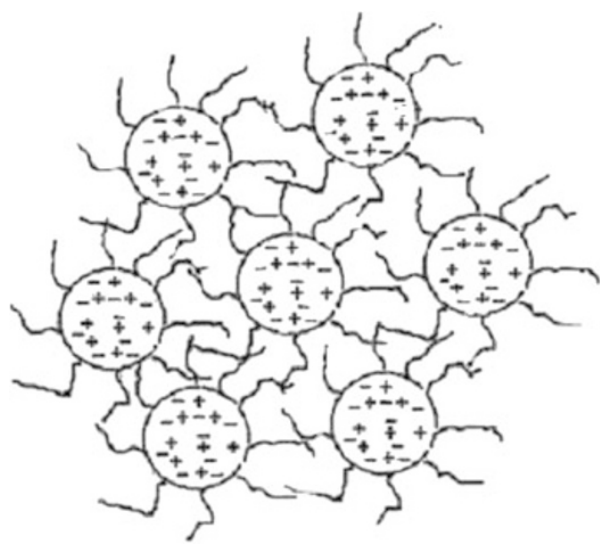

Figure 3. Illustration of micellar aggregates formed by poly( $\varepsilon$-caprolactone).

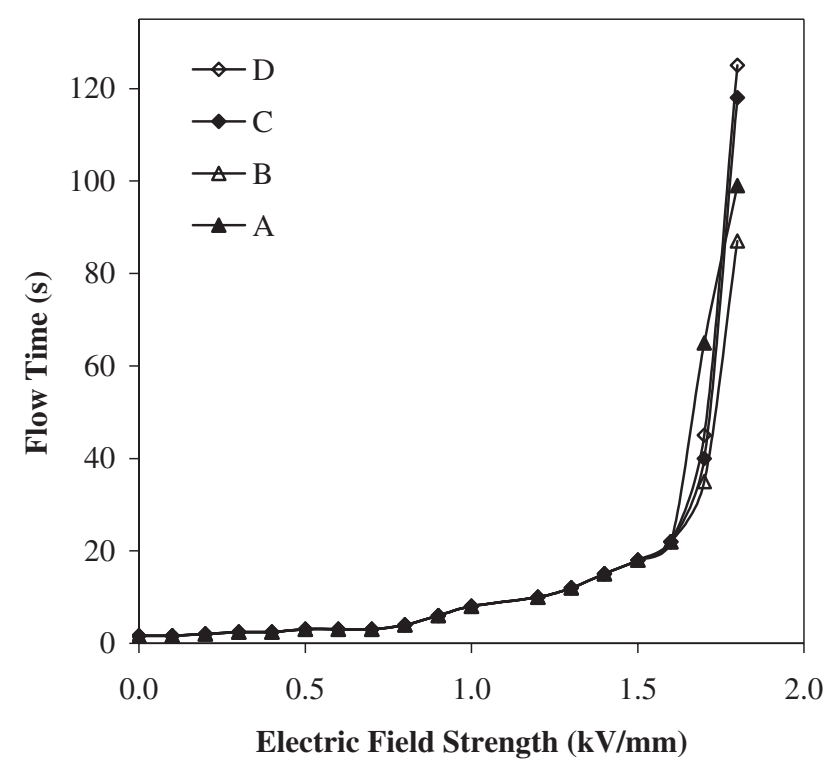

Figure 4. The change of flow times with electric field strength. $T=25^{\circ} \mathrm{C}, c=20 \%$.

flow time was started at $E=0.7 \mathrm{kV} / \mathrm{mm}$ and continued until $E=1.6 \mathrm{kV} / \mathrm{mm}$. After $E=1.6 \mathrm{kV} / \mathrm{mm}$ threshold energy $\left(E_{\mathrm{t}}\right)$ was supplied to the suspensions, a very sharp increase at the flow times was observed. This increase was highest for D/SO suspensions (for $E=1.8 \mathrm{kV} / \mathrm{mm}, \mathrm{t}=125 \mathrm{~s}$ ).

The flow times illustrated in Figure 4 are the maximum flow times, which could be measured under $E=1.8 \mathrm{kV} / \mathrm{mm}$. When $E$ was further increased, flow of the liquid between the electrodes was completely stopped and the measurement could not be made even after several hours waiting.

The maximum flow times of ionomer suspensions were increased with increasing $E$ and ionomer's molar mass and varied in the following order: D $(125 \mathrm{~s})>\mathrm{C}$ $(118 \mathrm{~s})>\mathrm{A}(99 \mathrm{~s})>\mathrm{B}(87 \mathrm{~s})$. The observed dependence of flow time on external electric field strength is also related to the changes in $\operatorname{poly}(\varepsilon$-caprolactone) 


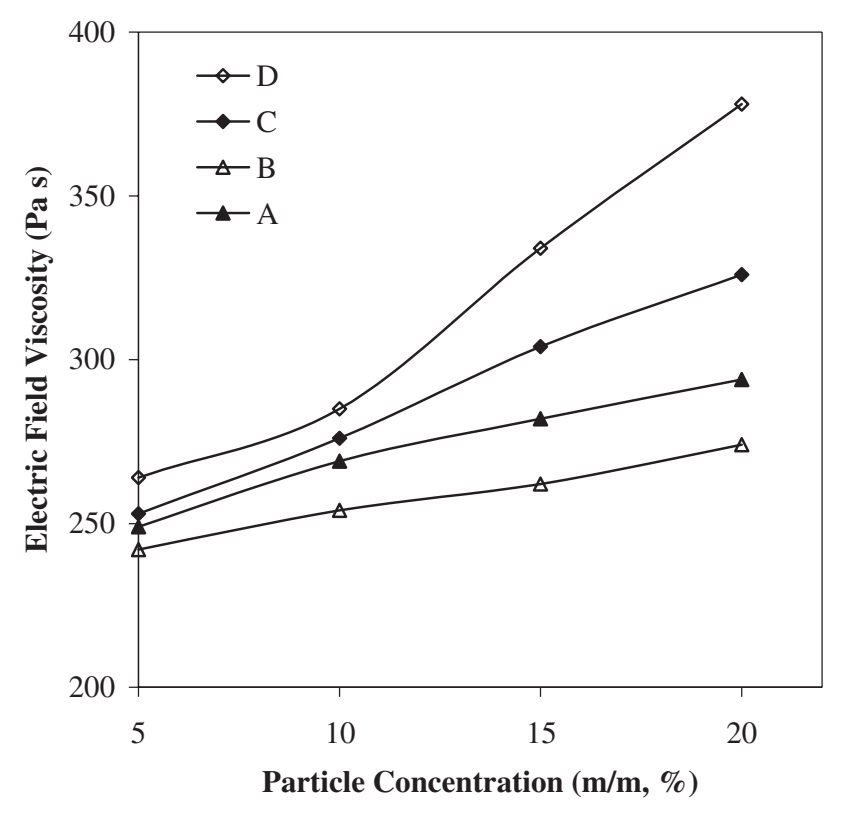

Figure 5. The effect of concentration of the particles in SO on the electric field viscosity. $E=2.0 \mathrm{kV} / \mathrm{mm}, \dot{\gamma}=1 \mathrm{~s}^{-1}, T=$ $25^{\circ} \mathrm{C}$.

molar mass of the polymers. As the molar mass of poly( $\varepsilon$-caprolactone) increases, possible interactions between particles and SO increases due to applied E. Similar behavior was reported for poly(Li-2-hydroxyethyl methacrylate), ${ }^{7}$ poly(Li-2-acrylamido-2methyl propane sulfonic acid $)^{9}$ and poly(Li-HEMA)$b$-(4-vinyl pyridine) copolymeric salt suspensions in SO. ${ }^{20}$

\section{Results Obtained from Electro-Rheometer Effect of Particle Concentration}

Figure 5 shows the influence of particle concentration and composition of polymers on the ER effect at field strength of $E=2.0 \mathrm{kV} / \mathrm{mm}$. With the application of $E=2.0 \mathrm{kV} / \mathrm{mm}$, the viscosities of the ionomer suspensions increased continuously for all the ionomers until $c=20 \%$ and then leveled off. The particle concentration and composition dependencies indicate that the ER activities of ionomers become higher with an increasing poly( $\varepsilon$-caprolactone) molar mass (see Table II). This trend is due to the polarization forces acting between the ionomeric particles.

The effect of ionomers concentration on the shear stress is given in Figure 6. As reflected from the figure, the ER activity of ionomers increases with increasing ionomer concentration, poly ( $\varepsilon$-caprolactone) mole ratio and the overall molar mass of the polymers. For $\mathrm{D} / \mathrm{SO}$ system, we obtained $\tau=7.4 \mathrm{kPa}$ shear stress (for $c=20 \%, \mathrm{~m} / \mathrm{m}$ ), which is well above the industrially desired $(\tau \geq 5 \mathrm{kPa})$ ER response. ${ }^{3}$ Under an external applied $E$, organization of ionomer particles take place in SO. The formation of particle fibers

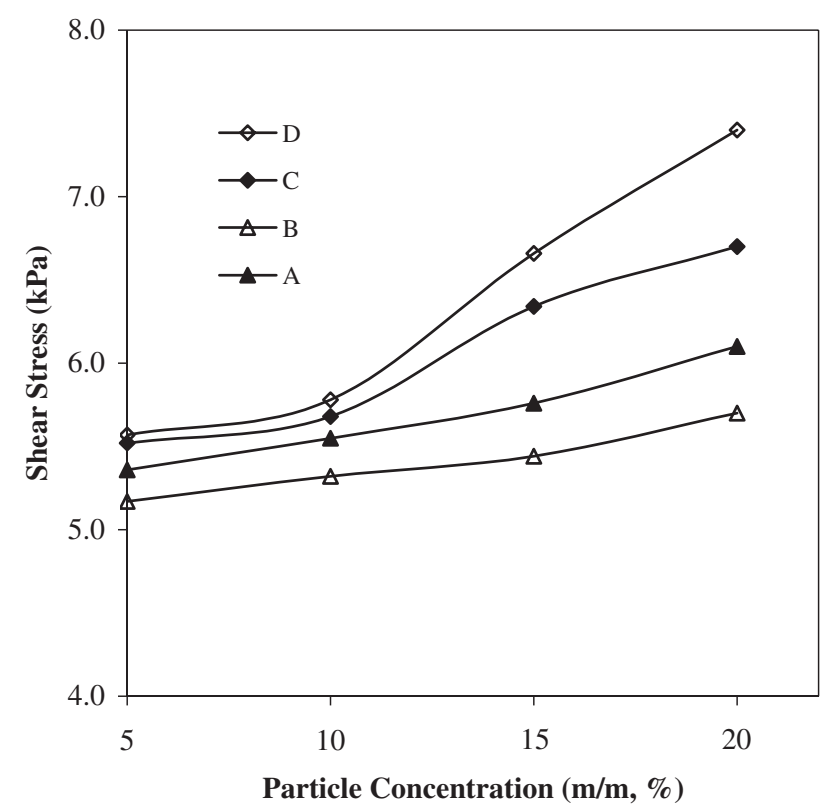

Figure 6. Effect of particle concentration on shear stress. $E=2.0 \mathrm{kV} / \mathrm{mm}, \dot{\gamma}=1 \mathrm{~s}^{-1}, T=25^{\circ} \mathrm{C}$.

in poly( $\varepsilon$-caprolactone) units is especially responsible for a marked ER effect. In an our pioneer study, for poly(Li-hydroxyethyl methacrylate)/SO system we observed $\tau=13.75 \mathrm{kPa}$ shear stress under the same conditions. $^{7}$ We believe that the presence of $\varepsilon$-CL units in the polymers also enhanced the magnitude of shear stress. Similar behavior was observed in the studies of PMMA- $b$-PSt/SO suspensions by Yilmaz et al., but they have reported maximum $\tau=280 \mathrm{~Pa}$ under $E=2.0 \mathrm{kV} / \mathrm{mm}^{21}$

\section{Effect of Electric Field Strength on Viscosity}

Electric field strength $(E)$ against electric field viscosity $\left(\eta_{\mathrm{E}}\right)$ (shear viscosity observed under an external applied electric field) obtained at $c=20 \%$ particle concentration is shown in Figure 7. The $\eta_{\mathrm{E}}$ of ionomers suspensions were increased with increasing $E$, poly( $\varepsilon$-caprolactone) the ionomers overall molar mass, and varied in the following order: D (378 Pas) > C (326 Pas) > A (294 Pas) > B (274 Pas). The $\eta_{\mathrm{E}}$ of $\mathrm{D} / \mathrm{SO}$ system is higher than all the other ionomers, as expected. Increase in the mole ratio of poly( $\varepsilon$-caprolactone) in polymers structure obviously enhanced polarizability of the ionomers in $\mathrm{SO}$ and does the ER activity.

When $E$ was applied to the suspensions, the polarization forces caused the aggregation of particles and fibril (or chain) formation between the plates occurred. This fibrillar structure is across the direction of the shear field and leads to an increased viscosity. Under an applied shearing force, the ionomeric particles are also acted on by the effects of viscous forces, which is due to the hydrodynamic interactions of par- 


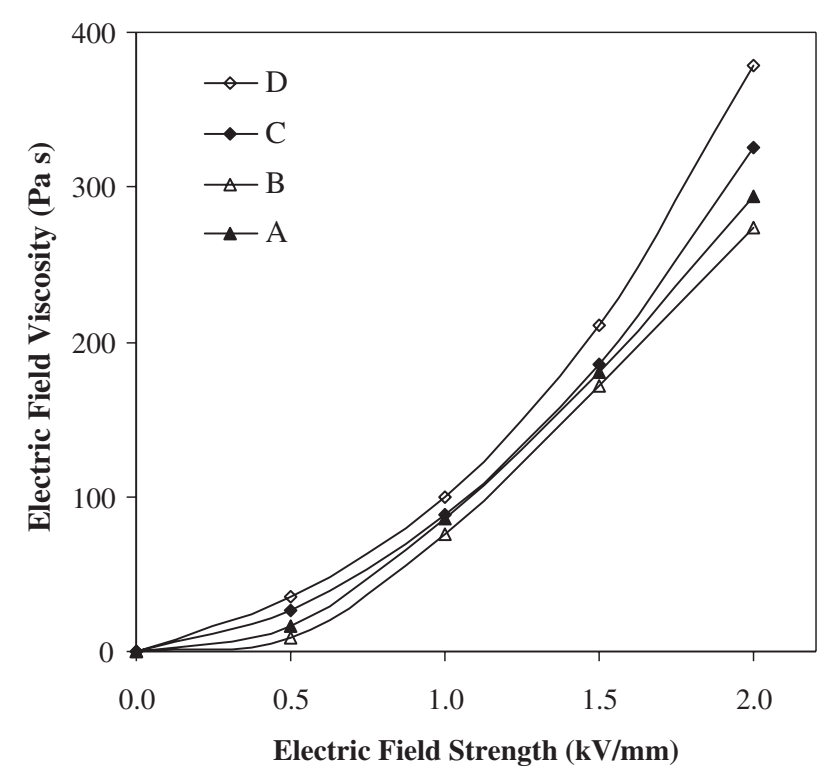

Figure 7. The change of viscosity with electric field strength. $T=25^{\circ} \mathrm{C}, c=20 \%, \dot{\gamma}=1 \mathrm{~s}^{-1}$.

ticles in the suspension.

The formation of particle chain structures in the electric field is reflected by the dependence of viscosity on $E$. Thus, when $E$ was increased, the apparent viscosity increased at least up to electrical saturation or electrical breakdown of the suspension.

\section{Change of Shear Stress with Electric Field Strength}

Figure 8 represents the change of shear stress $(\tau)$ with $\mathrm{E}$, which was obtained at constant suspension concentration $(c=20 \%)$, shear rate $\left(\dot{\gamma}=1.0 \mathrm{~s}^{-1}\right)$ and temperature $\left(T=25^{\circ} \mathrm{C}\right)$. As reflected from the graph, $\tau$ gradually increases with increasing $E$ up to $E=1.0$ $\mathrm{kV} / \mathrm{mm}$ and then a sharp increase is observed, which indicates that ER suspension become more stable under stronger applied $E$. As expected, the highest and the lowest $\tau$ values were obtained for $\mathrm{D} / \mathrm{SO}$ $(\tau=7.4 \mathrm{kPa})$ and $\mathrm{B} / \mathrm{SO}(\tau=5.7 \mathrm{kPa})$ suspensions, respectively. These observations are consistent with the results reported by Unal for poly(Li-hydroxyethyl methacrylate), ${ }^{7}$ by Yilmaz for poly(Li-2-hydroxy ethyl methacrylate)-co-poly(4-vinyl pyridine) ionomer ${ }^{22}$ and diatomite/SO suspensions. ${ }^{23}$

\section{Effects of Molar Mass and Polarization Forces on ER Activity}

Polymeric ER fluids can be classified in two categories. The first is materials having conjugated $\pi$ bonds. Two methods are generally used to control the conductivity of the conjugated material: doping a metallic ion or a metallic oxide. This type of materials could be highly polarized under an external $E$, thus they show a large dielectric constant. The second category is materials having a highly polarizable group on the molecu-

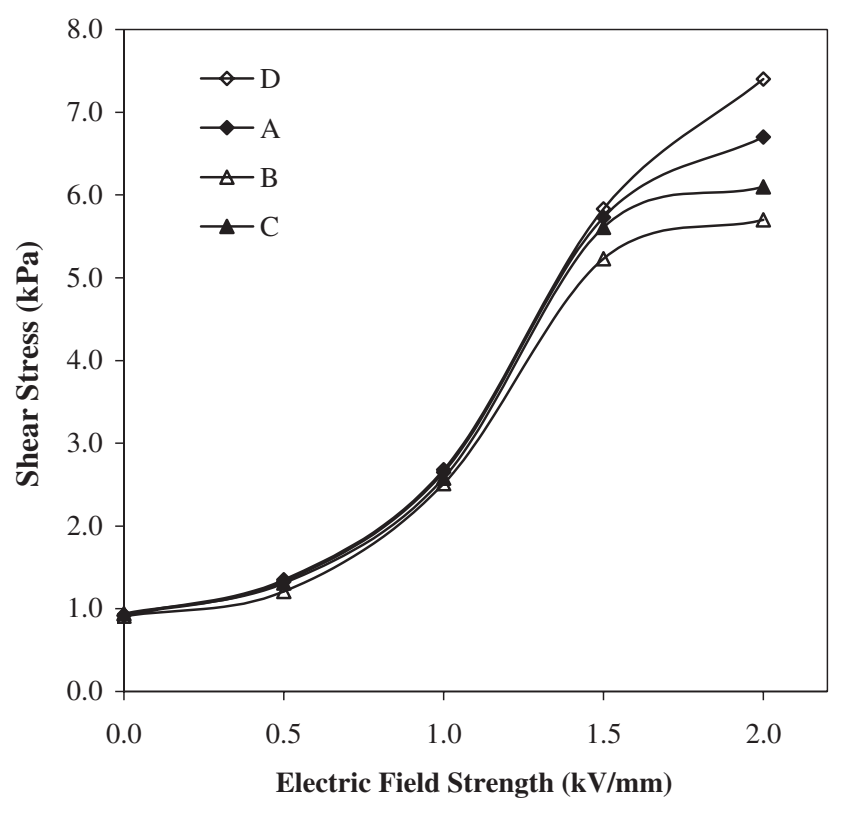

Figure 8. Change of shear stress of ionomers under different dc electric fields. $T=25^{\circ} \mathrm{C}, c=20 \%, \dot{\gamma}=1 \mathrm{~s}^{-1}$.

lar chain, such as hydroxyl, cyano, or amido, etc. ${ }^{3}$ Poly( $\varepsilon$-caprolactone) polymers are belong to this group. These polymers are polyelectrolyte, which have high molar mass and high charge density.

As we know, electrorheological behavior was associated with polarization of particles, migration of charge, and formation of columns. Besides the polarization of particles, the interaction of them is also important for electrorheological effect. So, the small electrorheological effect of the low molar mass PCL may be attributed to the weak interaction between PCL and their group induced under an electric field and a stronger interaction could be obtained if the PCL moieties were attached to the side chain of the polymer. On this assumption, the PCL was introduced into SO to improve the electrorheological effect.

The effect of molar mass of ionomers on the shear stress (or ER activity) of suspensions was studied at constant conditions $\left(\dot{\gamma}=1.0 \mathrm{~s}^{-1}, T=25^{\circ} \mathrm{C}, E=2.0\right.$ $\mathrm{kV} / \mathrm{mm}$ ). It is seen from Figure 9 that, shear stress of ionomers/SO system increases with increasing overall molar mass of the ionomeric polymer. This due is to the increased dielectric property B (1240) < A $(1263)<$ C $(1312)<$ D (1421), which result with enhanced ER response.

The shear stress increase is almost the same for D/ SO system under $E=2.0 \mathrm{kV} / \mathrm{mm}$ and we obtained $\tau=7.4 \mathrm{kPa}$. When the molar mass of poly ( $\varepsilon$-caprolactone) were increased, as reflected from Table I, first a sharp and then a gradual increase in shear stress were observed and we measured $\tau=1.7 \mathrm{kPa}$ shear stress increase. This is advantageous for ER active materials, because moderate polarization rate do maintain 


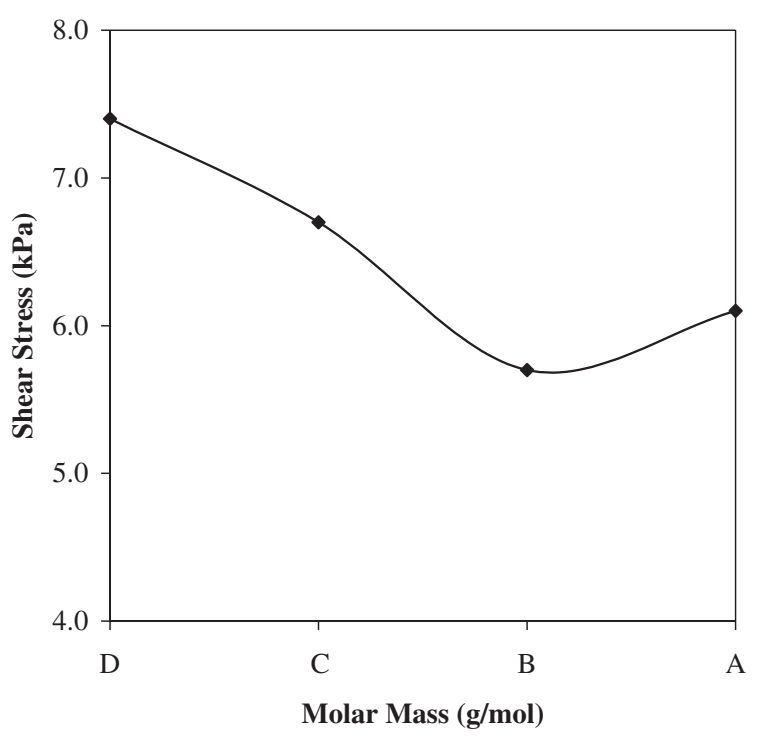

Figure 9. Change of shear stress with molar mass. $T=25^{\circ} \mathrm{C}$, $E=2.0 \mathrm{kV} / \mathrm{mm}, c=20 \%, \dot{\gamma}=1 \mathrm{~s}^{-1}$.

stable interaction or chain-like structure under electric field and shearing fields. ${ }^{24}$

When external electric field was applied to the ionomers suspensions, polarization forces caused aggregation of the particles, which resulted with the formation of fibrillar structures between the upper and lower plates. The relation of the magnitude of polarization forces $(F)$, with viscosity of suspension $\left(\eta_{s}\right)$, the average shear rate $(\dot{\gamma})$ and radius of particle $(r)$ can be written as:

$$
F=6 \pi \eta_{s} r^{6} \dot{\gamma}
$$

As seen from Figure 10 magnitude of polarization forces increase with increasing particle concentration, poly ( $\varepsilon$-caprolactone) mole ratio in the polymers. This is because that, as the particle concentration and poly( $\varepsilon$-caprolactone) mole ratio increases, the amount of polarizable $\varepsilon$-CL increase in the ionomer particles. As a result, the polarization forces between ionomer particles increases, and so does the suspension's ER effect. The highest polarization force was obtained for $\mathrm{D} / \mathrm{SO}$ system as $F=28 \times 10^{-23} \mathrm{~N}$, which has the highest poly $(\varepsilon$-caprolactone) molar mass. Effects of polarization forces on ER activity of various suspensions are reported in the literature. ${ }^{25}$

\section{Effect of Shear Rate and Shear Stress on Electric Field Viscosity}

Figure 11 shows the effect of shear rate and shear stress on electric field viscosity just for $\mathrm{D} / \mathrm{SO}$ system, at constant conditions $\left(c=20 \mathrm{wt} \%, T=25^{\circ} \mathrm{C}, E=\right.$ $2.0 \mathrm{kV} / \mathrm{mm}$ ). The electric field induced viscosity of suspensions was found to sharply decrease with increasing shear rate and giving a typical curve of shear thinning non-Newtonian visco-elastic behavior. As re-

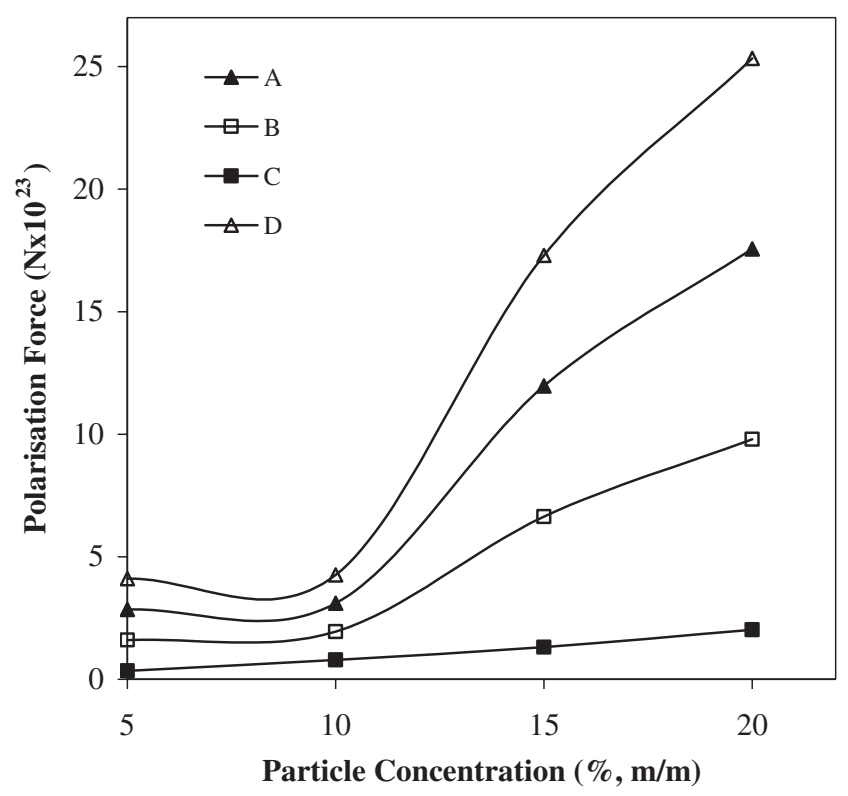

Figure 10. Change in electric field viscosity and polarization forces with suspension concentration. $E=2.0 \mathrm{kV} / \mathrm{mm}, \dot{\gamma}=1 \mathrm{~s}^{-1}$, $T=25^{\circ} \mathrm{C}$.

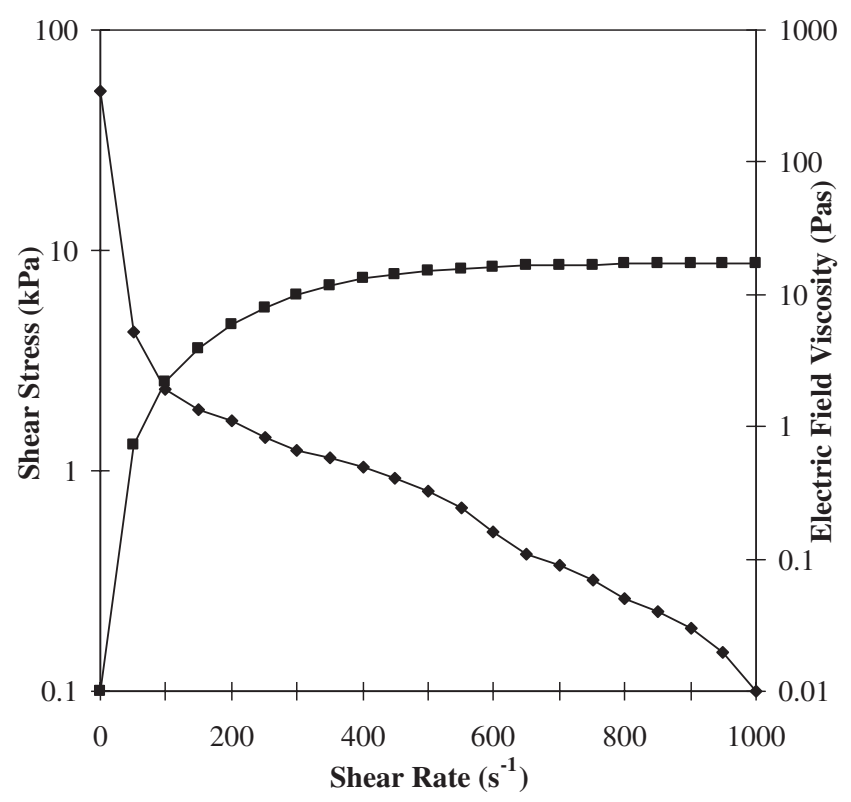

Figure 11. Change in viscosity and shear stress with shear rate.

flected from the graph, shear stress was increased with increasing shear rate and shown also typically nonNewtonian behavior and then become shear rate independent (Newtonian), which is a desired property in terms of potential industrial applications. Similar trends were determined for A-B-C/SO systems. These characteristic behaviors of the ER suspension are related to the internal particle structure induced by an applied external electric field. Before shearing the ER fluid, the dispersed particles are aligned through the electric field direction making columnar struc- 


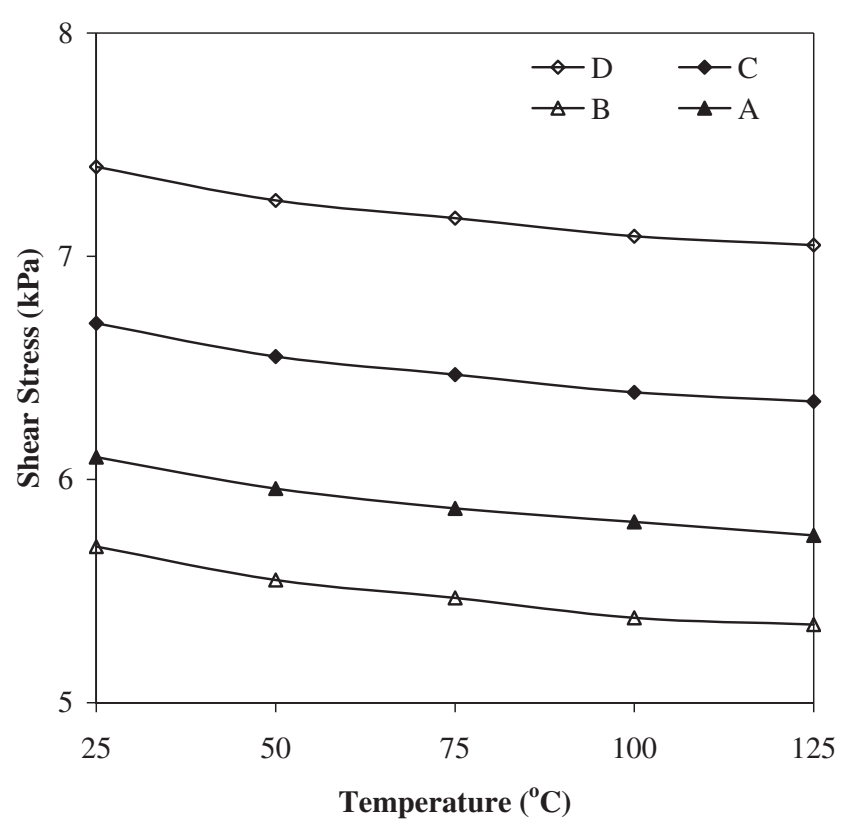

Figure 12. Effect of temperature on ER activity. $E=2.0 \mathrm{kV} /$ $\mathrm{mm}, c=20 \%, \dot{\gamma}=1 \mathrm{~s}^{-1}$.

tures, and these structures get stronger at higher electric fields. Similar results were reported for the studies of poly(Li-2-hydroxyethyl methacrylate), ${ }^{7}$ poly(lithium-2-acrylamido-2-methyl propane sulfonic acid) ${ }^{9}$ and calcium carbonate, ${ }^{19}$ in which silicone oil was used as continuous phase for the suspensions.

\section{Effect of Temperature on ER Activity}

Figure 12 shows the change in the shear stress of poly $(\varepsilon$-caprolactone)/SO suspensions under different temperatures at optimum concentration $(c=20 \%)$. For this kind of ER fluids, the ER effect is due to the polarization of mobile solid particles subjected to external $E$. Since the material's polarizability is temperature dependent, the shear stress of ER fluid is also influenced by the environment's temperature.

As reflected from the graph, we obtained a high shear stress $(\tau=7.4 \mathrm{kPa})$ for $\mathrm{D} / \mathrm{SO}$ system at $T=$ $25^{\circ} \mathrm{C}$ and this $\tau$ value slowly decreased with raising temperature and reached to $\tau=7.12 \mathrm{kPa}$ at $T=$ $125^{\circ} \mathrm{C}$. The loss at the $\tau$ of $/ \mathrm{SO}$ system for $\Delta T=$ $100^{\circ} \mathrm{C}$ temperature change is approximately $\Delta \tau=$ $0.35 \mathrm{kPa}$ (i.e., $2 \%$ ), which is extremely small $\tau$ loss in terms of potential high temperature industrial applications. In our pioneer study, for poly(Li-2-hydroxyethyl methacrylate)/SO system, we determined $\Delta \tau=$ $1.4 \mathrm{kPa}$ shear stress loss under the same conditions. ${ }^{7}$ This small shear stress drop for poly $(\varepsilon$-caprolactone)/SO system at high temperature may be attributed to the high polarizability of ionomers in structure, and also the possible formation of micellar structure in SO by ionomers.

The variability of ER activity with temperature is known to be a major problem with most conventional ER fluids and can limit their high temperature use. ${ }^{26}$ Similar behavior was reported by Kimura for gibbsite/SO suspension system. ${ }^{27}$

\section{Effect of Promoter on ER Activity}

Most ER suspensions contain additives such as surfactants or activators. The formers are added to improve colloidal stability of the dispersed particles but also to enhance the ER activity, while the presence of the latter is essential for the suspensions to display a significant ER response. The most common ER activator is water although there are also some other polar substances such as alcohols, ethylene glycol, dimethyl amine or formamide, which can activate ER suspensions. ${ }^{28}$ The disadvantages of promoter activated ER suspensions, so called wet ER fluids, (i.e., a restricted temperature range of operation and increased conductivity), have been overcome by the introduction of essentially promoter-free ER fluids, and classified as dry ER fluids. ${ }^{4}$

To determine the type of our D/SO system, whether dry or wet ER fluid, we added water and ethanol into the suspensions and carried out the ER measurements. We had electrical break down problems with water but obtained successful data with ethanol. In this article just the results obtained for $\mathrm{D} / \mathrm{SO}$ system containing $1000 \mathrm{ppm}$ ethanol is presented (Figure 13). It was observed that, the polymer system studied in the present work was almost insensitive to the amount of moisture present over the range studied, and may be classified as dry ER fluid. The electric field viscosity of the D/SO system was increased from $\eta_{\mathrm{E}}=378$ Pas to $\eta_{\mathrm{E}}=385$ Pas after the addition of

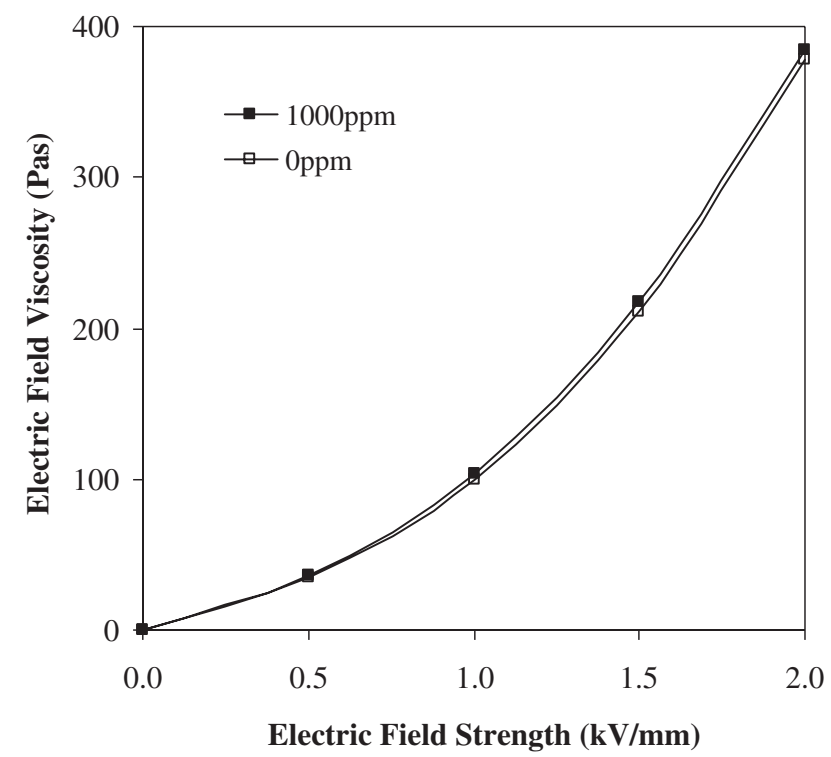

Figure 13. Effect of promoter on ER activity. Sample: D/SO suspension, $T=25^{\circ} \mathrm{C}, E=2.0 \mathrm{kV} / \mathrm{mm}, c=20 \%, \dot{\gamma}=1 \mathrm{~s}^{-1}$. 


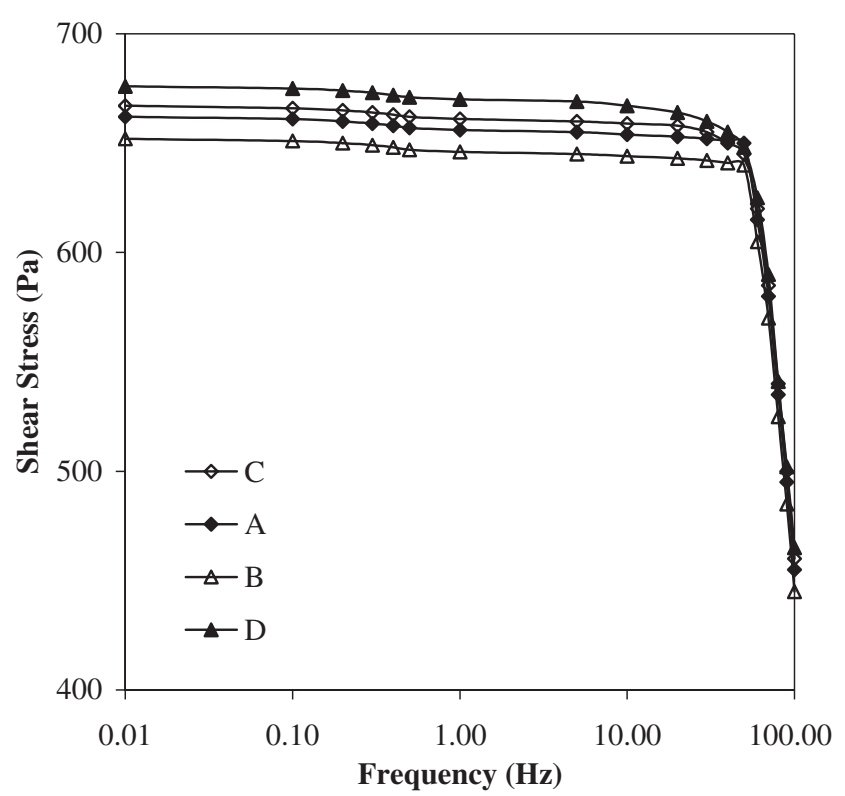

Figure 14. Effect of frequency on ER activity. $T=25^{\circ} \mathrm{C}$, $E=2.0 \mathrm{kV} / \mathrm{mm}, c=20 \%$.

$1000 \mathrm{ppm}$ ethanol. The most likely explanation is that the inherent polarisability of the ionic cores was sufficient to overweigh the effect of any adsorbed moisture. We observed similar behaviors in our previous studies. ${ }^{5,21,29}$

\section{Effect of Frequency on ER Activity}

A dc electric field is mostly used to generate a detectable ER effect. Since an ER fluid has a response time of approximately 1 millisecond, its viscosity and yield stress are expected to decrease with increasing frequency $(f)$, as it would be unable to catch up with the change of $E$ at high $f$. Change of ER activity of suspension with frequency at optimum suspension concentration $(c=20 \%)$ is shown in Figure 14. We observed that, until a definite value of $f$, the shear stresses of ionomers/SO systems were not changed with increasing $f$. But sharp decreases of the $\tau$ were found to occur for example for $\mathrm{D} / \mathrm{SO}$ system after $f=30 \mathrm{~Hz}$. A weakened particle interaction was expected at this point. The large dielectric constant enhancement and proper polarization response in this poly( $\varepsilon$-caprolactone)/SO ER fluids induce a strong and stable interaction between particles for high ER activity.

$\mathrm{Hao}^{30}$ reported that, the $\tau$ decrease corresponds to the decrease of dielectric constant of the whole suspension when $f$ increases. The particle conductivity determines whether the yield stress decrease appears at high or low $f$. High conductivity particles give an obvious ER effect even in very high $f$ fields, indicating a short response time.

The external stress frequency is an important factor

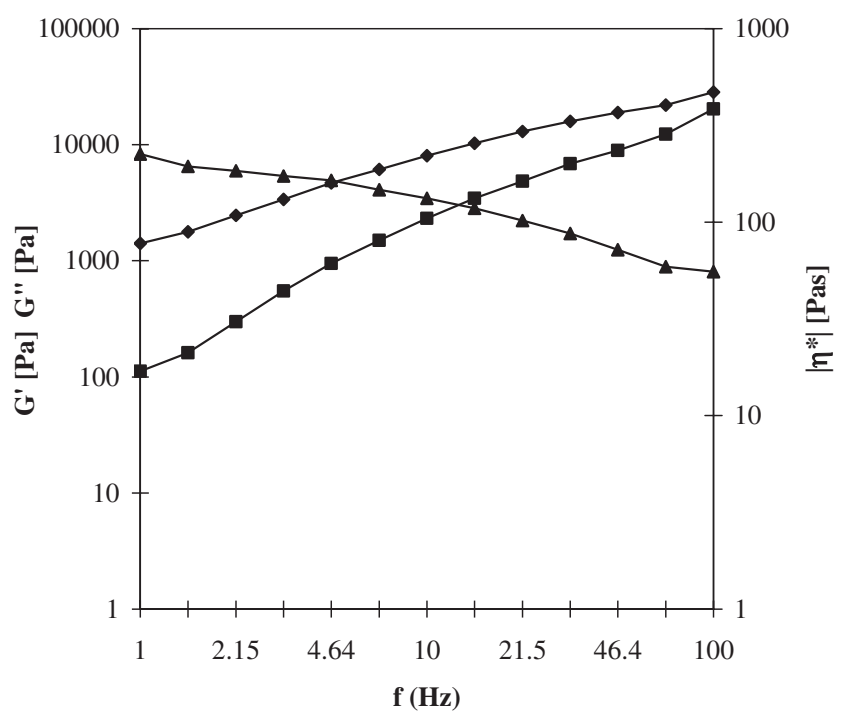

Figure 15. Effect of electric field frequency on visco-elastic parameters. (ם) $G^{\prime},(\diamond) G^{\prime \prime},(\boldsymbol{\Delta})\left[\eta^{*}\right]$, Sample: D/SO suspension, $T=25^{\circ} \mathrm{C}, E=2.0 \mathrm{kV} / \mathrm{mm}, c=20 \%$.

for characterizing the dynamic visco-elastic properties of ER fluids. ${ }^{31}$ Figure 15 shows the relationship of electric field $(E=2.0 \mathrm{kV} / \mathrm{mm})$ induced elasticity modulus $\left(G^{\prime}\right)$, loss modulus $\left(G^{\prime \prime}\right)$, kinematic viscosity $\left[\eta^{*}\right]$ and frequency $(f)$. The setting shear stress for this measurement was $\tau=10 \mathrm{~Pa}$, which ensures the measurements are conducted in the small strain region. As seen from the figure, ER activity (electric field induced kinematic viscosity) of ionomers/SO system decreases with increasing frequency, which may be attributed to the dielectric loss and low polarizability of the ionomer suspensions under high frequency conditions. $^{31}$

\section{CONCLUSIONS}

1. Colloidal stability of ionomers in SO was found to be $21 \mathrm{~d}$ for $\mathrm{D}$ suspensions at $c=5 \%$ concentration.

2. Flow time of suspensions was observed to increase with increasing electric field strength and suspension concentration. The highest flow time was obtained for $\mathrm{D} / \mathrm{SO}$ suspensions as $\mathrm{t}=125 \mathrm{~s}$ at $c=20 \%$ and $E=1.6 \mathrm{kV} / \mathrm{mm}$ conditions.

3. The ER response of all the poly( $\varepsilon$-caprolactone) suspensions was found to increase with increasing field strength up to $c=20 \%$ suspension concentration and then decrease.

4. ER activity of ionomer suspensions was observed to increase with increasing field strength and decreasing shear rate.

5. ER activity of ionomeric suspensions was observed to increase with increasing molar mass 
and molar mass of poly( $\varepsilon$-caprolactone) units.

6. Shear stress of polymers was found to sharply increase with increasing field strength.

7. It was observed that electric field viscosity of suspensions decreased sharply with increasing shear rate, and giving a typical shear-thinning non-Newtonian visco-elastic behavior.

8. It was found that the D/SO system studied in the present work was not sensitive to high temperature and moisture within the limits studied.

9. ER activity of polymers was found to sharply decrease applied frequency.

Acknowledgment. This work is supported by Harran University and Gazi University Research Fund.

\section{REFERENCES}

1. J. P. Coulter, K. D. Weiss, and J. D. Carlson, J. Intell. Mater. Sys. Struc., 4, 248 (1993).

2. K. D. Weiss, J. D. Carlson, and J. P. Coulter, J. Intell. Mater. Sys. Struc., 4, 13 (1993).

3. T. Hao, Adv. Colloid Interface Sci., 97, 1 (2002).

4. Z. P. Schulman, R. G. Gorodkin, E. V. Korobko, and V. K. Gleb, J. Non-Newtonian Fluid Mech., 8, 29 (1981).

5. R. Tao and G. D. Roy, "Electrorheological Fluids: Mechanisms, Properties, Technology and Applications," World Scientific Publishing Co, London, 1994.

6. H. Block, J. P. Kelley, A. Qin, and T. Watson, Langmuir, 6, 6 (1990).

7. H. I. Unal, O. Agirbas, and H. Yilmaz, Colloid Surf., A, 274, 77 (2006).

8. M. Degirmenci, G. Hizal, and Y. Yagci, Macromolecules, 35, 8265 (2002).

9. H. Yilmaz and H. I. Unal, J. Appl. Polym. Sci., 86, 1107
(2002).

10. H. Conrad, MRS Bulletin, 23, 35 (1998).

11. T. C. Halsey and W. Toor, Phys. Rev. Lett., 65, 2820 (1990).

12. D. J. Klingenberg and C. F. Zukoski, Langmuir, 6, 15 (1990).

13. P. Dong, C. Wang, and S. Zhao, Fuel, 84, 685 (2005).

14. Y. Tian, Y. Meng, and S. Wen, Mater. Lett., 50, 120 (2001).

15. R. M. German, "Powder Metalurgy Science, Material Powder Industries," Separation U.S.A, 1994, p. 28.

16. T. Uemura, K. Minagawa, and J. Takimoto, J. Chem. Soc., Faraday Trans., 91, 1051 (1995).

17. L. Rejon, A. Ramirez, F. Paz, F. M. Goycoolea, and M. A. Valdez, Carbohydr. Polym., 48, 413 (2002).

18. X. P. Zhao and X. Duan, Mater. Lett., 54, 348 (2002).

19. H. Yilmaz, H. I. Unal, and M. Yavuz, Colloid J., 67, 236 (2005).

20. H. Yilmaz and H. I. Unal, J. Appl. Polym. Sci., 101, 1065 (2006).

21. H. Yilmaz, M. Degirmenci, and H. I. Unal, J. Colloid Interface Sci., 293, 489 (2006).

22. H. Yilmaz and H. I. Unal, J. Appl. Polym. Sci., 99, 3540 (2006).

23. H. Yilmaz, Chin. J. Polym. Sci., 24, 463 (2006).

24. F. Ikzaki, A. Kawai, K. Uchida, T. Kawakami, K. Edmura, K. Sakurai, H. Anzai, and Y. Asako, J. Phys. D: Appl. Phys., 31, 336 (1998).

25. S. Wu and J. Shen, J. Appl. Polym. Sci., 60, 2159 (1996).

26. K. Tanaka and Y. Oiwa, Polym. J., 30, 171 (1998).

27. M. Kimura and M. Senna, Int. J. Inorg. Mater., 3, 363 (2001).

28. H. Block and J. P. Kelly, J. Phys. D: Appl. Phys., 21, 1661 (1988).

29. H. I. Unal, M. Yavuz, and H. Yilmaz, Gazi Univ. J. Sci., 14, 999 (2001).

30. T. Hao, J. Colloid Interface Sci., 206, 240 (1998).

31. B. D. Chin, Y. S. Lee, and O. O. Park, J. Colloid Interface Sci., 201, 172 (1998). 